\title{
OPEN
}

\section{Author Correction: A Genetic Screen for Investigating the Human Lysosomal CystineTransporter, Cystinosin}

\begin{abstract}
Anup Arunrao Deshpande, Anuj Shukla \& Anand Kumar Bachhawat
Correction to: Scientific Reports https://doi.org/10.1038/s41598-018-21483-x, published online 21 February 2018

This Article contained errors.

As a result of a figure assembly error, in Figure $5 \mathrm{~b}$ subpanel showing samples vps $1 \Delta$ through vaps $8 \Delta$ was duplicated for vps $25 \Delta$ through vps31 $\Delta$ and vps $53 \Delta$ through vps63 $\Delta$, for methionine treated samples. This same methionine sample was correctly shown in the Supplementary Information File.
\end{abstract}

Additionally, in the Supplementary Information file, as a result of labelling error, the label for vps $32 \Delta$ through vps38 $\Delta$ was duplicated for subsequent subpanel which instead should be labelled as vps39 $\Delta$ through vps $52 \Delta$.

These errors have now been corrected in the PDF and HTML versions of the Article, and in the accompanying Supplementary Information File.

(i) Open Access This article is licensed under a Creative Commons Attribution 4.0 International License, which permits use, sharing, adaptation, distribution and reproduction in any medium or format, as long as you give appropriate credit to the original author(s) and the source, provide a link to the Creative Commons license, and indicate if changes were made. The images or other third party material in this article are included in the article's Creative Commons license, unless indicated otherwise in a credit line to the material. If material is not included in the article's Creative Commons license and your intended use is not permitted by statutory regulation or exceeds the permitted use, you will need to obtain permission directly from the copyright holder. To view a copy of this license, visit http://creativecommons.org/licenses/by/4.0/.

(C) The Author(s) 2019

Indian Institute of Science and Education Research Mohali, Sector 81, Knowledge City, SAS Nagar, Punjab, India. Anup Arunrao Deshpande and Anuj Shukla contributed equally to this work. Correspondence and requests for materials should be addressed to A.K.B. (email: anand@iisermohali.ac.in) 